\section{The disruptive influence of syphilis cures within specialist venereal systems: implications for HIV cure preparedness}

\author{
Joseph D Tucker, ${ }^{1,2}$ Adriane Gelpi, ${ }^{2,3}$ David R Bangsberg, ${ }^{4,5,6}$ \\ Mary E Grewe, ${ }^{2,3}$ Raul Necochea ${ }^{3}$
}

The twentieth century has witnessed the rise of medical breakthroughs that have substantially decreased morbidity and mortality. Breakthroughs in curing specific diseases may transform the health systems designed to administer new cures. As potential cures move from the bench to the bedside, what was often originally conceived as a biomedical, frictionless intervention will be tested in the thorny, friction-filled and resource-constrained world of health service delivery. The historical trend of new cures influencing the social context of diseases and the health service delivery continues today. Clinical advances in curing HIV infection confirm the possibility of a cure, but these exciting research findings are still well in advance of implementation.

In contrast to earlier historical research that has focused on clinical consequences of new cures, this themed issue expands the analytical lens to consider the broader impact of sexually transmitted infection cures on health systems. For example, scholarship has examined several unanticipated clinical consequences of penicillin, including drug resistance, allergy and failure to treat viruses. But these clinical consequences may be less important than the dynamic health systems landscapes that shaped and were shaped by new cures. Prior to the development of Salvarsan, health systems intended to improve sexual health were fragmented. ${ }^{1}$ Paul Ehrlich's discovery of Salvarsan ${ }^{2}$ fundamentally reframed health systems to facilitate delivery of the new syphilis

\footnotetext{
${ }^{1}$ International Diagnostics Centre, London, UK; ${ }^{2}$ Institute for Global Health and Infectious Diseases, University of North Carolina at Chapel Hill, Chapel Hill, North Carolina, USA; ${ }^{3}$ Social Medicine Department, University of North Carolina at Chapel Hill, Chapel Hill, North Carolina, USA; ${ }^{4}$ Center for Global Health, Massachusetts General Hospital, Boston, Massachusetts, USA; ${ }^{5}$ Harvard Medical School, Boston, Massachusetts, USA; ${ }^{6}$ Harvard School of Public Health, Boston, Massachusetts, USA
}

Correspondence to Dr Joseph D Tucker, International Diagnostics Centre, Keppel Street, WC1E 7HT, London, UK; joseph.tucker@post.harvard.edu cure. $^{3}$ Then the more effective syphilis cure, penicillin, ${ }^{4}$ subsequently led to the slow death of venereology and health systems focused on delivering VD services. ${ }^{5}$ Curing syphilis would never be the same again. ${ }^{6}$

This history of syphilis cures and their influence on venereal disease systems may have implications for the development of HIV cures. Rendering HIV-infected people non-infectious with modern antiretroviral therapy has inspired research on HIV eradication strategies. As new HIV cure strategies reach later stages of clinical trials, it is unclear whether they will resemble what we now consider a partial cure like Salvarsan or a more complete cure like penicillin. Both Salvarsan and penicillin were introduced as complete cures, and their utility in clinical practice slowly became clearer over time. The early days of syphilis cure research and today's emerging HIV cure research have obvious differences, especially the relationship to wartime phenomena as each new syphilis cure was administered more widely during times of conflict. However, both syphilis cures were implemented well before the respective wars and their effects persisted well after the wars. A better understanding of the context of syphilis cures and their relationship to health systems may help guide the implementation of HIV cures as clinical trials advance.

One important lesson from the development of syphilis cures is the potential for newly developed cures, independent of clinical efficacy, to rapidly transform health systems designed to combat venereal diseases. The stagnant field of venereal disease was ignited after Salvarsan and nearly destroyed 35 years later with penicillin. Within the field of HIV, the development of antiretroviral therapy (ART) has profoundly shaped health delivery systems. The initial momentum to create separate, exceptionalist health systems initially launched in an era of

Table 1 Members of the Royal Commission on venereal disease, 1913-1916

\begin{tabular}{|c|c|c|}
\hline Name & Background & Coalitions (if known) \\
\hline $\begin{array}{l}\text { Lord Sydenham of } \\
\text { Combe }^{\star} \text {, F.R.S. }\end{array}$ & Defence expert and colonial administrator & $\begin{array}{l}\text { Sympathetic to imperial unity, } \\
\text { eugenics; against socialists } \\
\text { and feminist groups }\end{array}$ \\
\hline $\begin{array}{l}\text { Sir David Brynmor } \\
\text { Jones, K.C., M.P. }\end{array}$ & Welsh lawyer, historian, member of parliament & Liberal \\
\hline Sir Kenelm E. Digby & $\begin{array}{l}\text { Lawyer, undersecretary for state at the Home } \\
\text { Office }\end{array}$ & Gladstonian Liberal \\
\hline Sir Almeric FitzRoy & Lawyer, civil servant & \\
\hline $\begin{array}{l}\text { Sir Malcolm Morris, } \\
\text { F.R.C.S }\end{array}$ & Dermatologist and public health leader & \\
\hline $\begin{array}{l}\text { Mr. James Ernest Lane, } \\
\text { F.R.C.S }\end{array}$ & Surgeon and medical professor & Freemasons \\
\hline Sir John Colle, M.D. & $\begin{array}{l}\text { Medical examiner, member of parliament, } \\
\text { medical malpractice expert }\end{array}$ & Liberal \\
\hline Dr. Arthur Newsholme & $\begin{array}{l}\text { Chief Medical Officer for Local Government } \\
\text { Board, epidemiologist, health policy expert }\end{array}$ & \\
\hline Canon J. W. Horsley & Rector of St. Peter's Church, mayor & \\
\hline $\begin{array}{l}\text { Rev. John Scott } \\
\text { Lidgett, D. D. }\end{array}$ & $\begin{array}{l}\text { Methodist minister and Vice-Chancellor of the } \\
\text { University of London }\end{array}$ & $\begin{array}{l}\text { Liberal, leader of Progressive } \\
\text { Party }\end{array}$ \\
\hline $\begin{array}{l}\text { Dr. Frederick Walker } \\
\text { Mott, F.R.S. }\end{array}$ & Psychiatrist, neurologist and sociologist & \\
\hline $\begin{array}{l}\text { Mr. Philip Snowden, } \\
\text { M.P. }\end{array}$ & $\begin{array}{l}\text { Socialist politician, Member of parliament, } \\
\text { Chancellor of the Exchequer (1929-1931) }\end{array}$ & Labour party \\
\hline $\begin{array}{l}\text { Mrs. Mary Scharlieb, } \\
\text { M.D. }\end{array}$ & $\begin{array}{l}\text { Chief gynaecologist, midwife, forensic medicine } \\
\text { expert }\end{array}$ & Anglican, opposing contraception \\
\hline Mrs. Louise Creighton & Writer and social activist & Supported women's groups \\
\hline Mrs. Burdgwin & Teacher and superintendent & $\begin{array}{l}\text { Opposed women's suffrage and } \\
\text { sex education }\end{array}$ \\
\hline
\end{tabular}


toxic and partially effective mono and dual drug therapy has given way to a more integrationist approach with tolerable, highly effective therapies in recent years. ${ }^{7}$ Some general practitioners now treat HIV-infected individuals, ${ }^{8}$ and research on the relationship between HIV and non-communicable diseases is expanding. Yet the history of syphilis cures, ${ }^{9}$ penicillin in particular, highlights the inherent tension in a successful exceptional system. A partially effective HIV cure that requires an HIV specialist infrastructure could result in greater resource allocation to HIV compared with a relatively frictionless cure that obviates the need for HIV specialists altogether. The re-emergence of syphilis following the success of penicillin speaks to the potential unintended consequences of behavioural disinhibition at the individual level and insufficient long-term resources at the health systems level to realise global elimination. Similar unintended consequences of partially successful tuberculosis control programmes leading to relatively less funding have also been noted. ${ }^{10}$

The link between syphilis cures and subsequent syphilis control campaigns highlights the key role of policy stakeholders in translating new cures into implementable programmes. The Royal Commission served an important function as they defined the terms and scope of implementing Salvarsan in the UK. The composition of this Royal Commission (table 1) sparked controversy because it under-represented armed services personnel and women's groups who called for more structural reforms. The lack of a behavioural focus on the Commission was likely one reason that medical responses alone, rather than responses incorporating condoms alongside Salvarsan, became the dominant modus operandi during World War I venereal disease campaigns. Today a more diverse group of HIV stakeholders arrives at the issue, again with physicians playing a leadership role. The inclusion of behavioural scientists and implementation scientists as well as non-professional input from key populations would help ensure that cure strategies can be effectively implemented.

In addition to the unintended negative consequences outlined above, the history of syphilis cures also illuminates unintended positive consequences, suggesting that new cures expanded testing for screening and diagnostic purposes. Both Salvarsan and penicillin increased the number of individuals tested for syphilis. From the physician's perspective, sero-reversion (positive tests becoming negative) on diagnostic tests was the definition of curing syphilis and paved the way for increased work in this field. From the patient's perspective, knowing that syphilis was now curable may have lowered the barriers to seeking testing. Similar to Salvarsan, the development of HIV ART accelerated testing programmes and more ambitious disease control plans. The development of an HIV cure may further promote HIV testing programmes.

Curing HIV may be years or even decades away, but clinical trials have begun and there is building scientific momentum to cure HIV. The rich history of syphilis cures provides some guidance in this time of rapid flux. These historical lessons are not clear-cut answers, but may inspire dialogue to help us better inform the implementation of HIV treatment and ultimately cure programmes.

Acknowledgements The authors would like to thank Dr Lesley Hall at the Wellcome Library and Dr Kevin Brown at the Alexander Fleming Laboratory Museum for archival assistance and Catie Gliwa for administrative assistance.

Contributors All authors drafted this manuscript, revised for critical content and approved the final version.

Funding Support for this work was provided by the Brocher Foundation, the UNC Center for AIDS Research (NIAID P30-Al50410) and the Social and Ethical Aspects of Research on Curing HIV Working Group (NIAID R01A108366-01). The Working Group's composition and rationale is explained at $h t t p: / /$ searchiv.web.unc.edu/
Competing interests None.

Provenance and peer review Commissioned; internally peer reviewed.

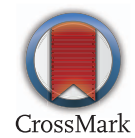

To cite Tucker JD, Gelpi A, Bangsberg DR, et al. Sex Transm Infect 2015;91:2-3.

Received 7 September 2014

Accepted 27 September 2014

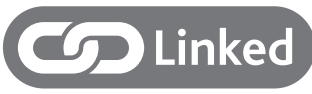

- http://dx.doi.org/10.1136/sextrans-2014-051778

- http://dx.doi.org/10.1136/sextrans-2014-051779

- http://dx.doi.org/10.1136/sextrans-2014-051780

http://dx.doi.org/10.1136/sextrans-2014-051781

- http://dx.doi.org/10.1136/sextrans-2014-051782

http://dx.doi.org/10.1136/sextrans-2014-051783

Sex Transm Infect 2015;91:2-3.

doi:10.1136/sextrans-2014-051777

\section{REFERENCES}

1 Gelpi A, Tucker JD. After Venus, mercury: syphilis treatment in United Kingdom before Salvarsan. Sex Transm Infect 2015;91:68

2 Gelpi A, Gilbertson A, Tucker JD. Magic Bullet: Paul Ehlrich, Salvarsan and the Birth of Venereology. Sex Trans Infect 2015;91:69.

3 Gelpi A, Tucker JD. The magic bullet hits many targets: Salvarsan's impact on UK health systems, 1909-1943. Sex Transm Infect 2015;91:70.

4 Gelpi A, Tucker JD. A cure at last? Penicillin's unintended consequences on Syphilis control, 1944-1964. Sex Transm Infect 2015;91:71.

5 Gilbertson A, Gelpi A, Tucker JD. The impact of penicillin on sexual healthcare delivery systems in mid-20th century Britain. Sex Transm Infect 2015;91:72-3

6 Grewe ME, Tucker JD. Syphilis cure posters. Sex Transm Infect 2015;91:71-2.

7 Bayer R. Public health policy and the AIDS epidemic. An end to HIV exceptionalism? N Engl J Med 1991;324:1500-4.

8 Wong WC, Kidd MR, Tucker JD. Mainstreaming HIV services for men who have sex with men: the role of general practitioners. Sex Transm Infect 2012;88:566-7.

9 Brown K. Pox: the life and near death of a very social disease. London: The History Press, 2006.

10 Macaraig M, Burzynski J, Varma JK. Tuberculosis control in New York City-a changing landscape. N Engl J Med 2014;370:2362-5. 